\title{
Rupture of an Experimentally Induced Aneurysm in a Primate
}

\author{
F. Espinosa, B. Weir, T. Noseworthy
}

\begin{abstract}
SUMMARY: Cerebral aneurysms are extremely rare in all animals except man. We report the occurrence of a carotid-ophthalmic aneurysm in a cynomolgous monkey two months following accidental occlusion of the ipsilateral cervical internal carotid artery. This was documented angiographically. The aneurysm was deliberately ruptured by the insertion and withdrawal of fine needles. This produced a large subarachnoid hemorrhage visualized on CT scan. There was a progressive severe fall in cerebral blood flow and moderate vasospasm. The neurological status deteriorated on the tenth day and the animal was sacrificed on day 13 . On electron microscopy, the aneurysm showed a fibrous wall, and the endothelium showed balloon-like endothelial cells with gaps. Corrugations occurred in the inner aspect of the anterior circulation arteries.
\end{abstract}

RÉSUMÉ: Les anévrysmes cérébraux sont extrêmement rares chez tous les animaux sauf l'homme. Nous rapportons un anévrysme carotidienophtalmique chez un singe, deux mois après l'occlusion accidentelle de l'artère carotide interneipsilatérale sans sa portion cervicale. Cette occlusion fut documentée à l'angiographie. L'anévrysme fut délibérément rupturé à l'aiguille, produisant une énorme hémorragie sous-arachnoidènne visible à la tomodensitométrie. Cet évènement fut suivie d'une baisse sévère du flot cérébral et de vaso-spasmes modérés. L'état neurologique s'est détérioré au 10e jour et l'animal fut sacrifié le 13e jour. A la microscopie électronique, l'anévrysme avait une paroie fibreuse et l'endothélium montrait des cellules gonflées avec des espaces vides. Les artères anérieures étaient endommagées.

Can. J. Neurol. Sci. 1984: 11:64-68

There is only one previous report of an aneurysm being induced in a primate and that occurred following direct vessel injury (Harvey and Downer, 1975). We report here the first case in a nonhuman primate in which the production of an aneurysm was induced by internal carotid occlusion. Once it was documented by angiography, the aneurysm was deliberately ruptured. This resulted in a fall in cerebral blood flow, a late neurological deterioration which became so severe that sacrifice was necessary, and morphological changes in the cerebral arteries surrounded by the most blood.

\section{MATERIALS AND MethodS}

A female cynomolgous monkey (Macaca fascicularis) weighing $3.6 \mathrm{~kg}$ was studied. This animal had induction of general anesthesia and surgical exposure of the left common carotid artery. A 20 gauge plastic catheter was placed into the lumen of the artery via a 7-0 purse-string suture. A needle was then placed in the chiasmatic cistern for the artificial induction of a subarachnoid hemorrhage (SAH). Angiography showed a normal left intracranial carotid circulation and no aneurysm at the carotid-ophthalmic junction. Subsequent angiography following the SAH showed non-filling intracranially and only slight flow in some external carotid branches. It was assumed that the manipulations of the catheter had occluded the internal carotid artery. The experiment was therefore aborted and the needle in the subarachnoid space and catheter in the internal carotid were withdrawn. Anesthesia was reversed and the animal was returned to its cage. It recovered without any obvious hemiparesis. Two months later when it was neurologically normal, it was restudied by retrograde femoral angiography. The animal was found to have a left ophthalmiccarotid aneurysm.

In a subsequent operation, two small needles were placed directly into the dome of the aneurysm via a right pterional approach (the dome projected towards the right). When the incisions were closed, the strings attached to the needles were withdrawn while the animal was still under anesthesia. Angiography was repeated 1 hour, 3, 7 and 13 days post-rupture. Prior to angiography, hemispheric blood flows were measured using the intra-arterial Xenon ${ }^{133}$ technique. CT scans were performed before the initial femoral angiogram and on day 0 following the induced aneurysmal rupture, and on the third and seventh days thereafter, using a GE $8800 \mathrm{CT}$ scanner. On each occasion, anesthesia consisted of pentobarbital $26 \mathrm{mgm} / \mathrm{kg}$ and $\mathrm{N}_{2} 0: 0_{2}$ in a $2: 1$ ratio.

Neurological examination was conducted daily. By day 13, the condition was one of immobility and inability to eat. The animal was sacrificed by in vivo perfusion-fixation carried out with buffered $2 \%$ gluteraldehyde at $110 \mathrm{mmHg}$.

The brain was removed, the vessels and aneurysm were photographed and dissected. Light, scanning and transmission electron microscopic studies were performed.

From the Division of Neurosurgery and the Department of Medicine, Faculty of Medicine. The University of Alberta

Received August 25, 1983. Accepted in revised form November 22, 1983

Requests for reprints to: Dr. B.K.A. Weir, 11-102 Clinical Sciences Building, The University of Alberta, Edmonton. Alberta, Canada T6G 2G3 

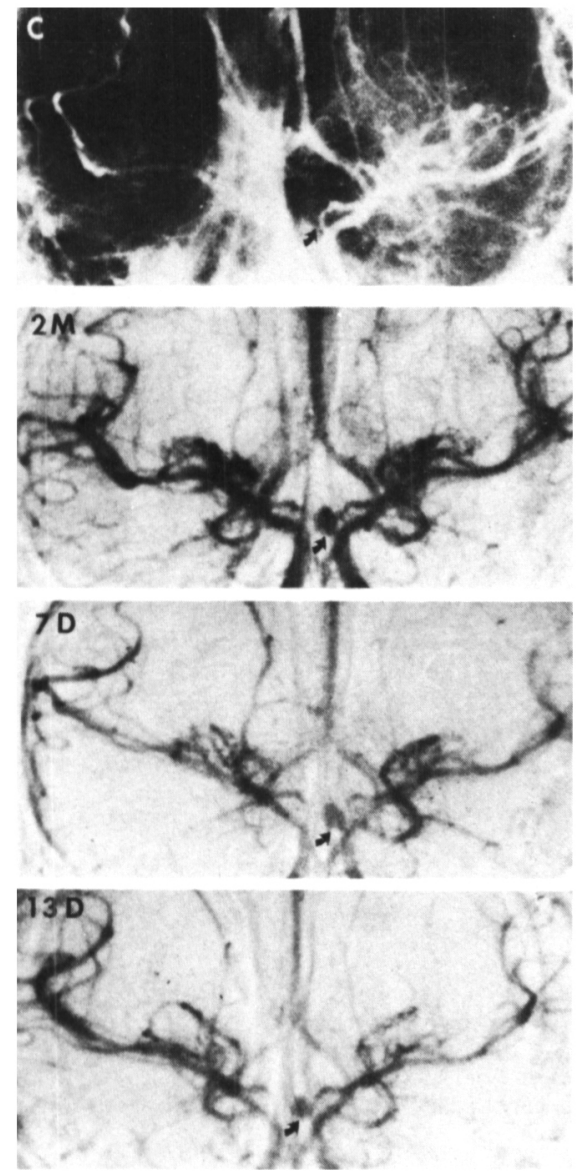

Figure I - " $C$ " - oblique view from initial angiogram showing no aneurysm at ophthalmic-carotid junction. " $2 M$ " - anteroposterior angiogram showing saccular $3 \mathrm{~mm}$ aneurysm at carotid-ophthalmic junction (black arrow). " $7 D$ " - angiogram 7 days post-rupture, some chronic vasospasm is present. " $13 D$ " - angiogram done just before sacrifice showing aneurysm and some residual vasospasm.

\section{RESULTS}

\section{Angiography}

The initial left carotid angiogram was normal. Following this angiogram the internal carotid could no longer be visualized. A $3 \mathrm{~mm}$ aneurysm at the junction of the internal carotid artery (which later filled normally) and the ophthalmic artery was visualized two months later. The needle for placement of blood in the chiasmatic cistern, which entered via a low mid-line twist drill hole, was not near the site of aneurysm development and the relatively large clinoids and planum were between the needle tip and the ophthalmic artery origin. At postmortem, there was no evidence of bony penetration. It was not possible to reach the aneurysm or adjacent carotid via the twist drill hole under direct vision with the skull open at post mortem examination.

Fig. 1 demonstrates the initially normal carotid angiogram (oblique view) and the subsequent aneurysm seen at two months (arrow). The aneurysm was ruptured by the placement of 2 fine needles attached to sutures under direct microsurgical exposure of the aneurysm dome and their subsequent withdrawal after closure of the craniotomy. There was vasospasm seen in subsequent studies and evidence of a right sylvian mass indicated by straightening of the sphenoidal portion of the middle cerebral artery. Vessel calibre had not returned to normal by day 13.

\section{CT Scan}

A large subarachnoid hematoma was evident on the initial post-SAH scan. This had been almost completely reabsorbed by day 7 . No obvious infarcts were seen (see Fig. 2).

\section{Cerebral Blood Flow}

Xenon ${ }^{133}$ intra-arterial blood flow measurements showed initial hemispheric values of $63-65 \mathrm{ml} / 100 \mathrm{gm} / \mathrm{min}$. This fell to 15 $\mathrm{ml} / 100 \mathrm{gm} / \mathrm{min}$ by day 13 post-SAH (see Fig. 3).
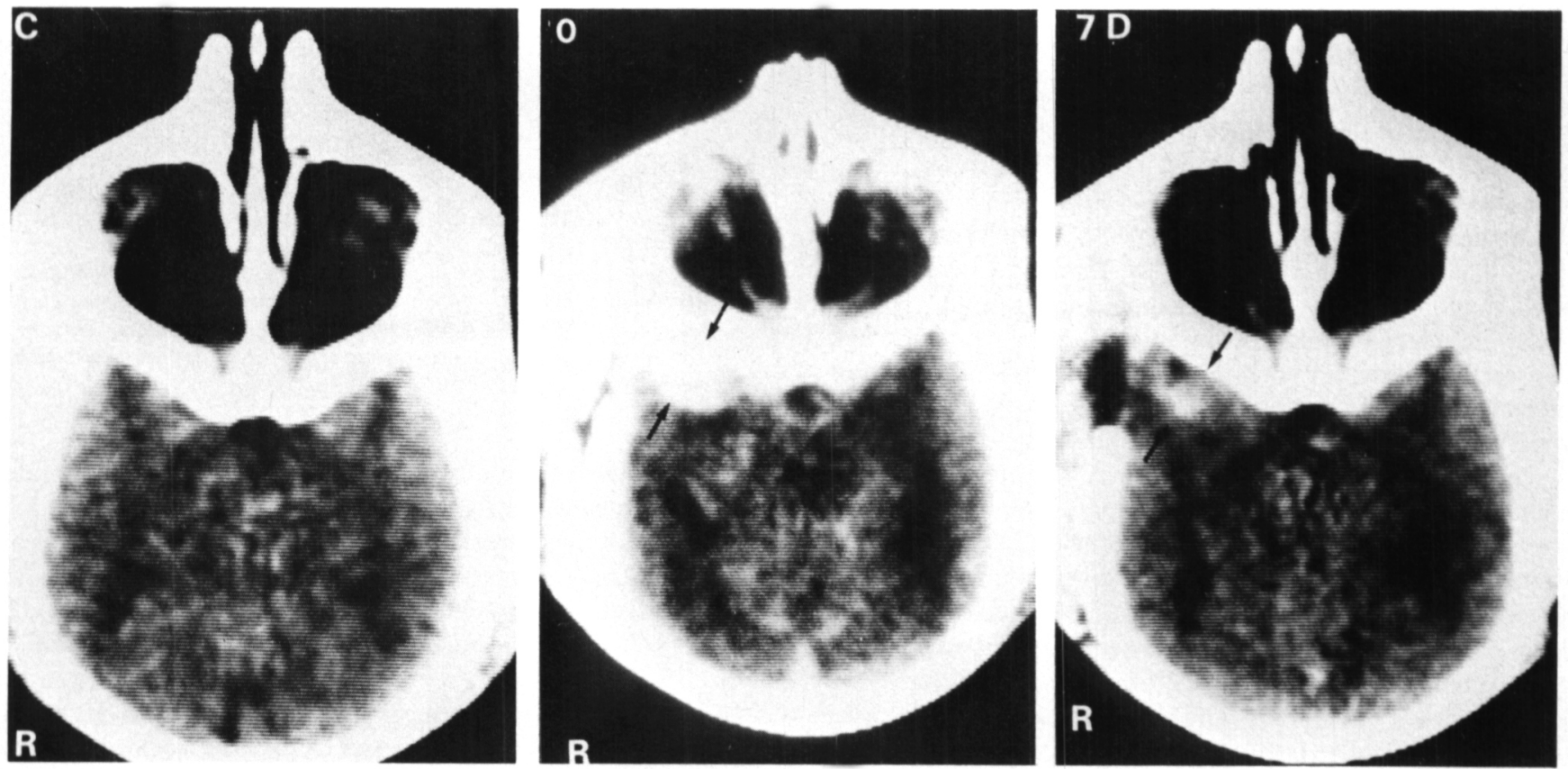

Figure $2-$ " $C$ " - control CT scan done 2 months after initial study in which left carotid artery showed non-filling. " $O$ " - CT scan showing large right-sided subarachnoid hematoma several hours following rupture of the aneurysm. " $7 D$ " - almost complete disappearance of hematoma at 7 days. 


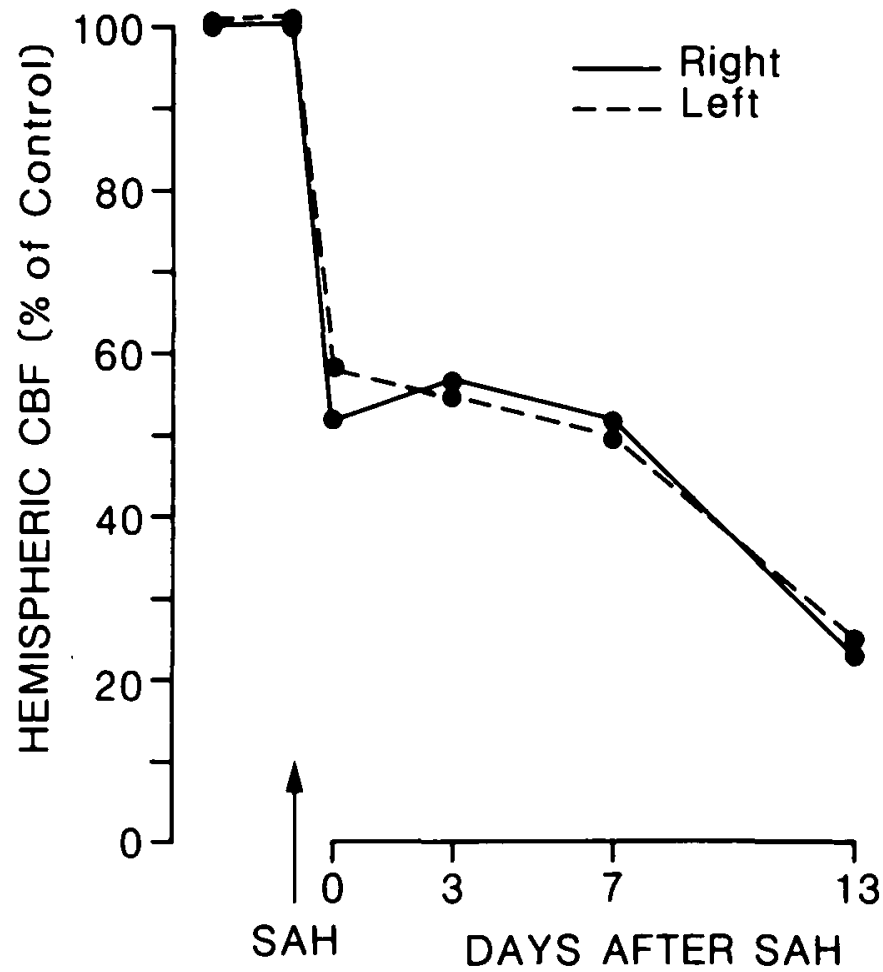

Figure 3-Hemispheric cerebral blood flow as a percentage of control value shows steady and progressive fall with both hemispheres being equally affected.

\section{Neurological Status}

For the first five days following the rupture of the aneurysm, the animal was lethargic. Between the sixth and ninth days, it appeared to be normal. On the tenth and eleventh days, it became lethargic again and was immobile and generally weak by day 12 . It was sacrificed on day 13 .

\section{Pathological Studies}

The aneurysm was $3 \mathrm{~mm}$ in diameter and spherical in shape. The walls were of uniform thickness. The subarachnoid space was stained but the clot, for the most part, had been reabsorbed. There was no evidence of infection.

Light microscopy of the aneurysm wall showed a fibrous wall lacking elastica and media. There was a significant fibrinoid layer. An inflammatory cellular response was absent.

Scanning electron microscopy of the endothelium showed ballooning of some cells, crater formations and adherence of platelets and leucocytes to some of the gaps and pits (Fig. 4, top). The cut edge of the aneurysm showed multiple fibrous lamellae with neovascularization of the adventitial aspect (Fig. 4 , middle). The adjacent subarachnoid space contained collagen fibres and erythrocytes in various stages of breakdown (Fig. 4, bottom). The luminal surface showed corrugations or intimal folds which were parallel to the direction of blood flow. These folds were most marked in the middle cerebral on the side of the largest subarachnoid clot (Fig. 5, top), less on the opposite middle cerebral (Fig. 5, middle) and absent in the normal appearing basilar artery (Fig. 5, bottom). The middle cerebral arteries should look like the lower panel following gluteraldehyde pertusion at greater than mean blood pressure.
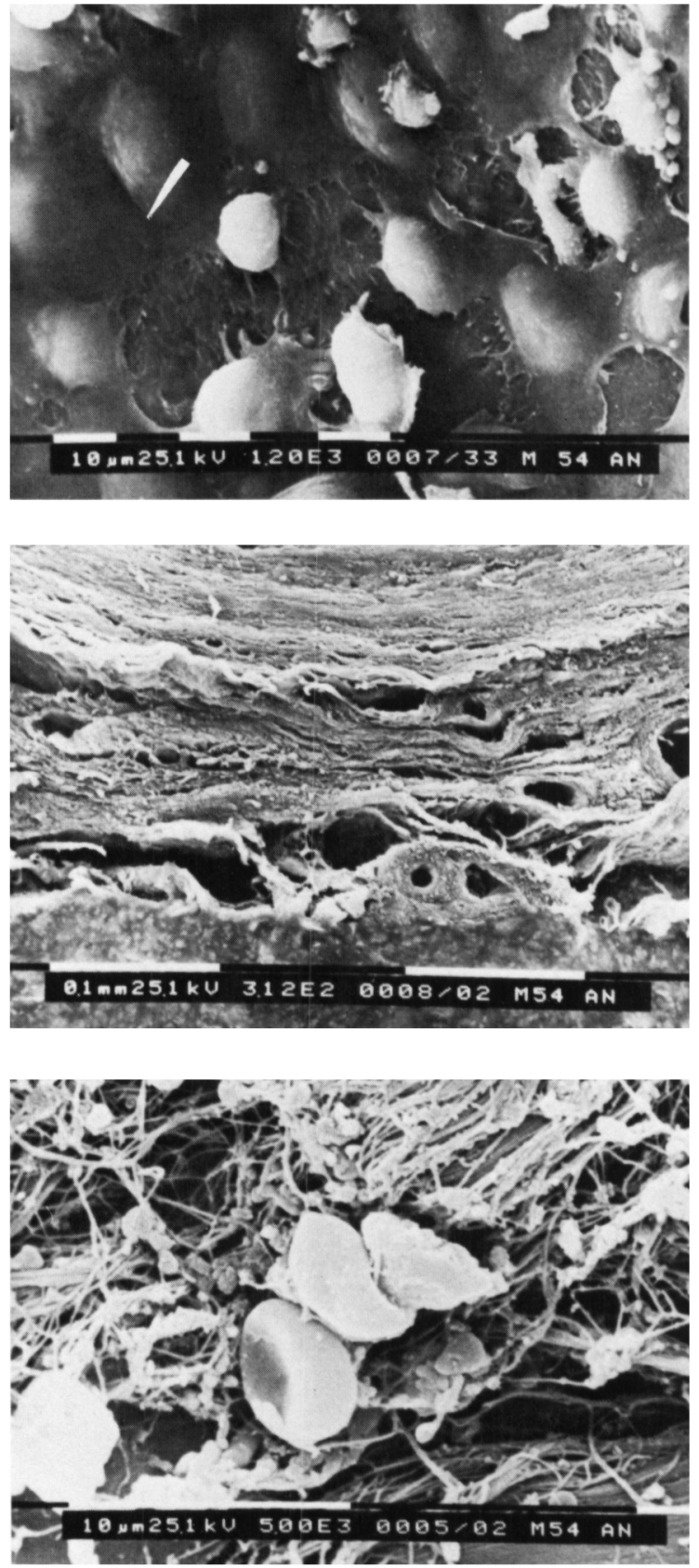

Figure 4 - Top - luminal surface of the aneurysm by scanning electron microscopy. Middle - cut edge of aneurysmal wall by scanning electron microscopy. Bottom - subarachnoid space adjacent to aneurysm showing collagen fibers and degenerating erythrocytes by scanning electron microscopy.

Transmission electron microscopy showed the greatest corrugations in the right middle cerebral artery (Fig. 6, left). The apex of these crests consisted of loose, aveolar spaces and contorted or corkscrew-like smooth muscle nuclei in the media. The elastica was markedly undulated and the endothelium looked intact. There was no subendothelial proliferation. Similar less marked changes were seen in the left middle cerebral artery (Fig. 6, middle) while the basilar artery looked relatively normal (Fig. 6, right). The aneurysm wall lacked a muscularis layer and was formed mainly of fibroblasts, collagen fibers and amorphous material. 

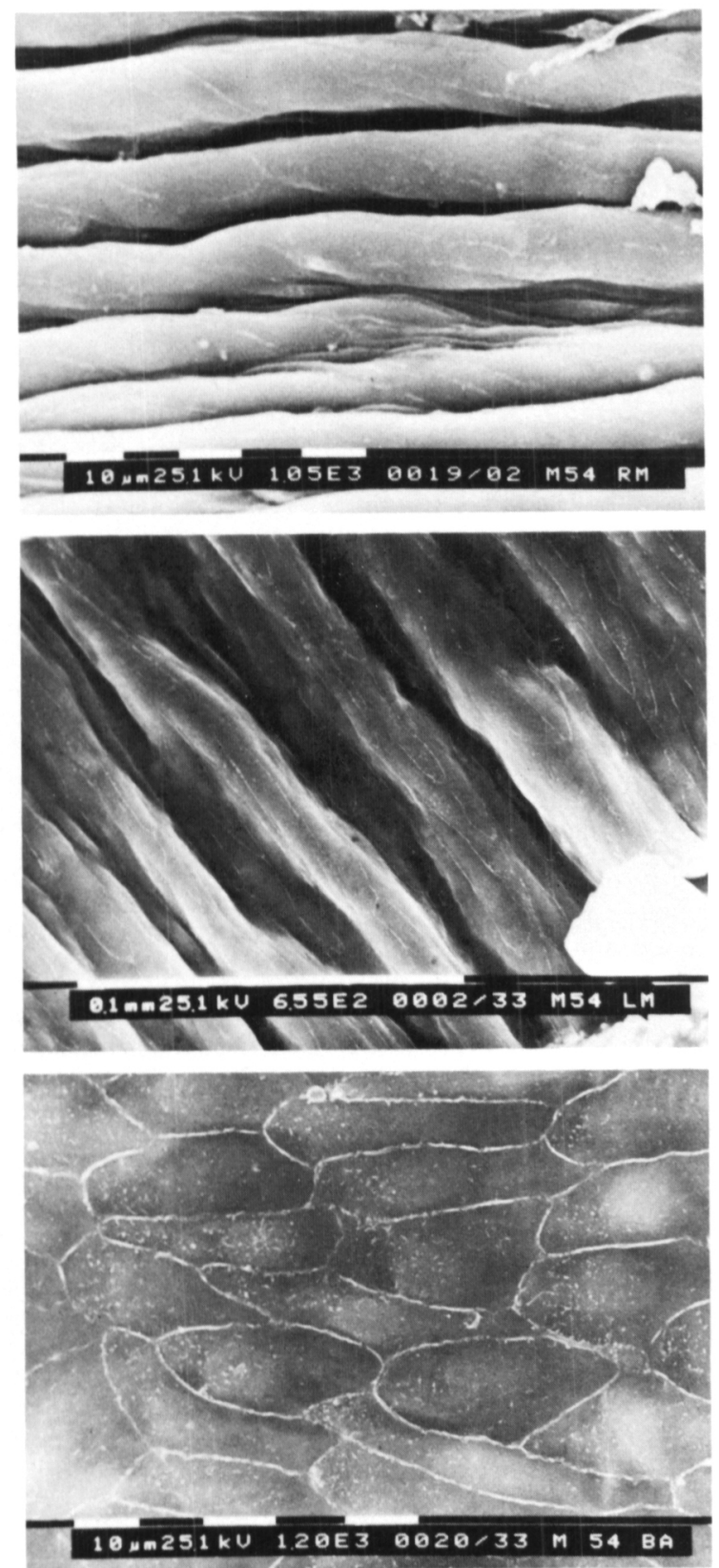

Figure 5 - Scanning electron microscopyofvessels.Top-endothelial surface of right middle cerebral artery which was surrounded by large clot in CT scan. Middle - endothelial surface of the left middle cerebral artery. Bottom - endothelial surface of the basilar artery. This is the normal appearance of arterial endothelial surface.

\section{Discussion}

A reliable model for human cerebral aneurysms would be of great importance in advancing our knowledge of subarachnoid hemorrhage and its sequellae. The various animal models which have been proposed are summarized in Table 1. There are severe limitations to all of them and the only one which is reliably produced intracranially is the rat model. An essential feature is the litigation of at least one carotid artery. It is likely that the induction of the aneurysm in our case was a consequence of transient carotid occlusion. There was probably reversal and increase of flow through the left ophthalmic artery. Direct injury to the artery at the site of the aneurysm was ruled out by the autopsy finding of unpenetrated dense bone between the aneurysm site and the frontal twist drill hole.

Naturally occurring cerebral aneurysms in non-human primates are extremely rare but have been reported in chimpanzees by Stehbens (1963) and Andrus et al. (1968).

There are two human cases of aneurysm developing on the contralateral internal carotid artery several years after cervical carotid artery ligiation, when the aneurysms were not demonstrated on the original angiograms (Salar and Mingrino, 1981). Sixteen cases of human aneurysms associated with congenital absence of the cervical carotid artery have been reported (Waga et al., 1978). Sixty-three percent of the aneurysms were on the anterior communicating artery and $19 \%$ at the basilar bifurcation. Presumably these sites are subjected to compensatory increase in flow and increase in hemodynamic stress.

This sporadic case was useful in that the physiological results of the induced rupture resembled observations in human patients. The morphological changes also were consistent with our primate model of simulated subarachnoid hemorrhage by clot placement on exposed intracranial arteries. The structure of the aneurysm resembled, in some respected, the previous electron microscopic descriptions in animals (Suzuki et al., 1980; Nagata et al., 1981; Greenhill and Stehbens, 1982). If this case could be reduplicated, it would make a useful model of the human intracranial aneurysm.

\section{Table 1: Methods for induction of cerebral aneurysms in animals}

Method Species Author(s)

1. Injection of necrotizing solutions into arterial wall

a) nitrogen mustard

dog

b) hypertonic saline

$\operatorname{dog}$

McCune et al. (1953)

2. Carotid ligation to increase contralateral hemodynamic stress

$\begin{array}{ll}\text { rabbit } & \text { Hassler (1963) } \\ \text { rabbit } & \text { Uchida (1974) } \\ \text { rat } & \text { Hashimoto et al. } \\ & (1978,79,80) \\ \text { rat } & \text { Suzuki }(1980)\end{array}$

3. Induced hypertension to increase hemodynamic stress

a) deoxycorticosterone and salt

b) renal infarction

c) Goldblatt technique

rat

rat

rat

Hashimoto (1978)

Nagata et al. (1980)

Suzuki et al. (1980)

4. Angiolathyrism to damage elastica ( $\beta$-aminoproprionitrile)

rabbit rat

Uchida (1974)

Hashimoto et al.

$(1978,79,80)$

rat

Nagata et al. (1980)

rat

Suzuki et al. (1980)

5. Venous patch graft to arteries a) common carotid trunk and bifurcation

b) basilar-lingual anastamosis site

$\operatorname{dog}$

$\operatorname{dog}$

rat

sheep \&

rabbit

dog

German \& Black

(1954 \& 60)

Mullan et al. (1964)

Nishikawa et al. (1976)

Stehbens (1979\& 81)

(d)

Siqueira et al. (1980)

dog

Nishikawa et al. (1977)

6. Arterial trauma
Harvey \& Downer (1975) 

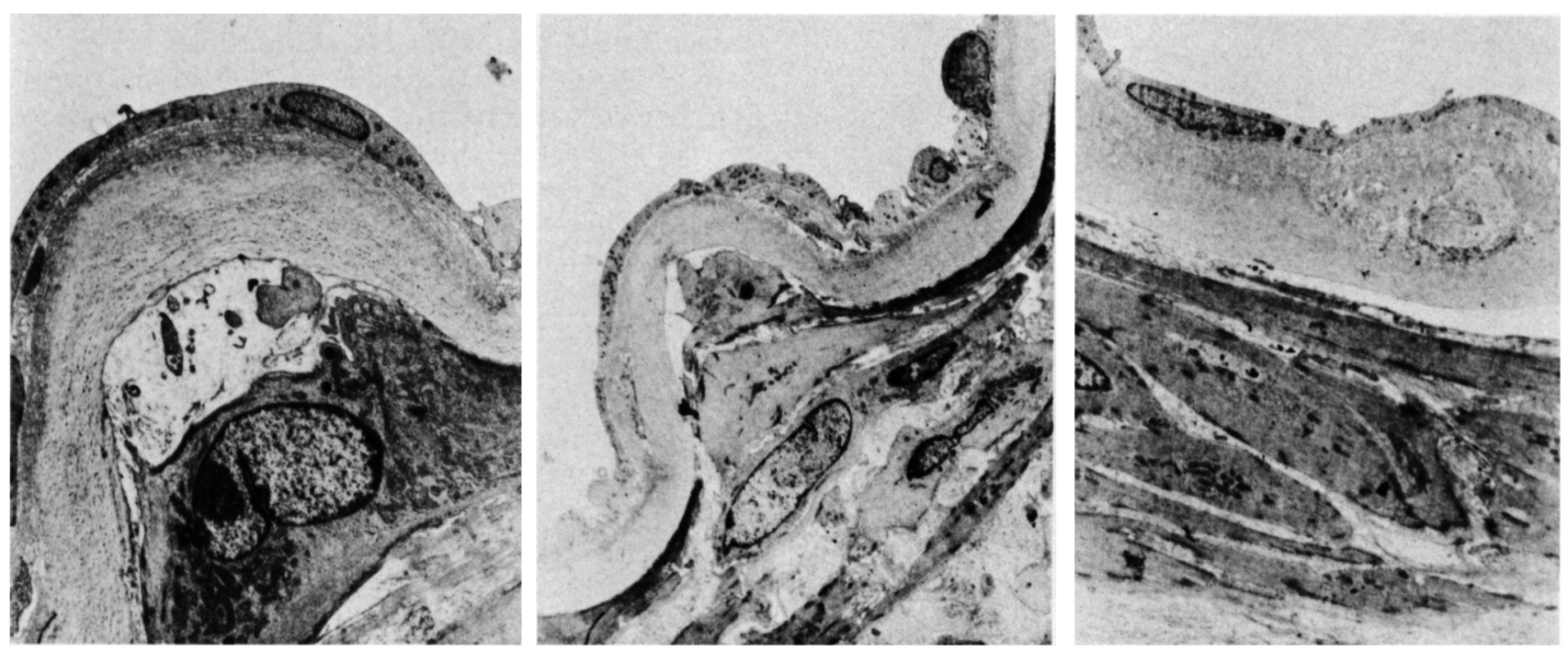

Figure 6 - Transmission electron micrographs of cerebral vessels. Left - right middle cerebral artery. Note marked undulation of the intima, and marked contraction of a smooth muscle nucleus and edema of the media $(x 9900)$. Middle - left middle cerebral artery. Note moderate undulation of the intima, rounding of endothelial cells and myolysis within the media $(x 5600)$. Right - basilar artery with normal looking endothelium, elastic lamina and muscularis $(x$ 9900).

\section{REFERENCES}

Andrus, S.B., Portman, O.W., Riopelle, A.J. (1968). Comparative studies of spontaneous and experimental atherosclerosis in primates. II. Lesions in chimpanzees including myocardial infarction and cerebral aneurysms. Progr. Biol. Biochem. Pharm. 4: 393-419.

Black, S.P.W., German, W.J. (1960). Observations on the relationship between the volume and the size of the orifice of experimental aneurysms. J. Neurosurg. 17: 984-990.

German, W.J., Black, S.P.W.(1954). Experimental production of carotid aneursyms. New Engl. J. Med. 250: 104-106.

Greenhill, N.S., Stehbens, W.E. (1982). Scanning electron-microscopic study of the inner surface of experimental aneursysms in rabbits. Atherosclerosis 45 : 319-330.

Harvey, F.H., Downer, J.L. (1975). Traumatic production of an intracranial berry-like aneurysm in a monkey. Acta Neuropath. (Berlin) 31:263-266.

Hashimoto, N., Handa, H., Hazama, F. (1978). Experimentally induced cerebral aneurysms in rats. Surg. Neurol. 10: 3-8.

Hashimoto, N., Handa, H., Hazama, F. (1979). Experimentally induced cerebral aneurysms in rats. Part II. Surg. Neurol. 11:243-246.

Hashimoto, N., Handa, H., Hazama, F. (1979). Experimentally induced cerebral aneurysms in rats: Part III. Pathology. Surg. Neurol. 11: 299-304.

Hashimoto, N., Handa, H., Nagata, I., Hazama, F. (1980). Experimentally induced cerebral aneurysms in rats: Part V. Relation of hemodynamics in the Circle of Willis to formation of aneurysms. Surg. Neurol. 13:41-45.

Hassler, O. (1963). Experimental carotid ligation followed by aneurysmal formation and other morphological changes in the Circle of Willis. J. Neurosurg. 20: 1-7.

McCune, W.S., Samadi, A., Blades, B. (1953). Experimental aneurysms. Annals Surg. 138: 216-218.

Mullan, S., Beckman, F., Vailati, G. Karasick, J., Dobben, G. (1964). An experimental approach to the problem of cerebral aneurysm. J. Neurosurg. 21: 838-845.
Nagata, l., Handa, H., Hashimoto, N., Hazama, F. (1980). Experimentally induced cerebral aneurysms in rats: Part VI. Hypertension. Surg. Neurol. 14: 477-479.

Nagata, I., Handa, H., Hashimoto, N., Hazama, F. (1981). Experimentally induced cerebral aneurysms in rats: VII. Scanning electron microscope study. Surg. Neurol. 16: 291-296.

Nishikawa, M., Smith, R.D., Yonekawa, Y. (1977). Experimental intracranial aneurysms. Surg. Neurol. 7: 241-244.

Nishikawa, M., Yonekawa, Y., Matsuda, I. (1976). Experimental aneurysms. Surg. Neurol. 5: 15-18.

Salar, G., Mingrino, S. (1981). Development of intracranial saccular aneurysms: Report of two cases. Neurosurgery 8: 462-465.

Siqueira, M.G., Galeno Rojas, R.A., Sturion, D.J. (1980). Aneurysmas experimentais. Propo sicao de nova tecnica. Arqu. Neuro-Psiquiat. 38: 18-23.

Stehbens, W.E. (1963). Cerebral aneurysms of animals other than man. J. Path. Bact. 86: 161-168.

Stehbens, W.E. (1979). Chronic changes in the walls of experimentally produced aneurysms in sheep. Surg. Gyn. Obstet. 149: 43-48.

Stehbens, W.E. (1981). Chronic changes in experimental saccular and fusiform aneurysms in rabbits. Arch. Path. Lab. Med. 105: 603-607.

Stehbens, W.E. (1981). Predilection of experimental arterial aneurysms for dietary-induced lipid deposition. Pathology 13: 735-747.

Suzuki, S., Robertson, J.T., White, R.P., Stadlan, E.M., Popoff, N. (1980). Experimental intracranial aneurysms in rats. A gross and microscopic study. J. Neurosurg. 52: 494-500.

Uchida, M. (1974). Electron microscipical studies on the arteries of brain basis. II. Saccular aneurysm in rabbit and human cases Kumamoto Med. J. 27: 150-169.

Waga, S., Okada, M., Kojima, T. (1978). Saccular aneursyms associated with absence of the left cervical carotid areteries. Neurosurgery 3 : 208-212.

White, J.C., Sayre, G.P., Whisnant, J.P. (1961). Experimental destruction of the media for the production of intracranial arterial aneurysms. J. Neurosurg. 18: 741-745. 